Franco, RM, Carriço, MRS, Galarça, RCG \& Silva, FF. (2020). Socio-anthropological research: dialogical strategy for the construction of the preliminary diagnosis of school reality. Research, Society and Development, 9(7): 1-20, e514974330.

\title{
Pesquisa socioantropológica: estratégia dialógica de construção do diagnóstico preliminar da realidade escolar
}

Socio-anthropological research: dialogical strategy for the construction of the preliminary diagnosis of school reality

Investigación socioantropológica: estrategia dialógica para construir el diagnóstico preliminar de la realidad escolar

Recebido: 14/05/2020 | Revisado: 14/05/2020 | Aceito: 15/05/2020 | Publicado: 24/05/2020

Ronan Moura Franco

ORCID: http://orcid.org/0000-0001-7237-2258

Universidade Federal do Pampa, Brasil

E-mail: rmourafranco@gmail.com

Murilo Ricardo Sigal Carriço

ORCID: http://orcid.org/0000-0002-9169-3070

Universidade Federal do Pampa, Brasil

E-mail: murilocarrico@gmail.com

Rita Cristina Gomes Galarça

ORCID: http://orcid.org/0000-0001-6912-8676

Secretaria Municipal de Educação, Brasil

E-mail: ritagalarca@gmail.com

Fabiane Ferreira da Silva

ORCID: http://orcid.org/0000-0002-0608-4490

Universidade Federal do Pampa, Brasil

E-mail: fabianeunipampa@gmail.com

\section{Resumo}

Este trabalho objetiva descrever as etapas do processo de construção e desenvolvimento da Pesquisa Socioantropológica. A pesquisa socioantropológica configura-se enquanto uma abordagem qualitativa de caráter investigativo para o conhecimento da realidade. Foi realizada por integrantes do Programa Institucional de Bolsa de Iniciação à Docência, subprojeto Ciências da Natureza em uma escola pública municipal de Uruguaiana, no Rio 
Grande do Sul. Os fundamentos teóricos e metodológicos utilizados baseiam-se na aproximação com etapas da Investigação Temática freireana, sendo questionários semiestruturados os instrumentos de produção das informações. A pesquisa socioantropológica possibilitou conhecer características específicas da comunidade escolar investigada, tais como questões relacionadas a aspectos econômicos, sociais, culturais e ambientais. Como resultado do processo investigativo foi elaborado o diagnóstico preliminar da realidade que foi entregue à direção da escola, com a promessa de considerar a pesquisa na revisão do Projeto Político Pedagógico da escola, o que pode possibilitar a construção de práticas educativas contextualizadas.

Palavras-chave: Pesquisa socioantropológica; Investigação temática; Escola.

\begin{abstract}
This research aims to describe the stages of the construction process and development of Socio-anthropological Research. The socio-anthropological research is set up as a qualitative approach of investigative character for the knowledge of reality. It was carried out by members of the Institutional Program for Teaching Initiation Scholarship, a Natural Sciences subproject in a municipal public school in Uruguaiana, Rio Grande do Sul. The theoretical and methodological foundations used are based on the approximation with stages of Freire's Thematic Research, being semi-structured questionnaires the instruments of information production. The socio-anthropological research allowed to know specific characteristics of the investigated school community, such as issues related to economic, social, cultural and environmental aspects. As a result of the investigative process, a preliminary diagnosis of the reality was delivered to the school board, with the promise of considering the research in the revision of the school's Political Pedagogical Project, which may enable the construction of contextualized educational practices.
\end{abstract}

Keywords: Socio-anthropologial research; Thematic investigation; School.

\title{
Resumen
}

Este trabajo tiene como objetivo describir las etapas del proceso de construcción y desarrollo de la Investigación Socioantropológica. La investigación socioantropológica se configura como un enfoque cualitativo de carácter investigativo para el conocimiento de la realidad. Fue realizado por miembros del Programa de Becas Institucionales para la Iniciación a la Enseñanza, subproyecto de Ciencias de la Naturaleza en una escuela pública municipal en Uruguaiana, en Rio Grande do Sul. los cuestionarios semiestructurados son los instrumentos 
para la producción de información. La investigación socioantropológica permitió conocer características específicas de la comunidad escolar investigada, tales como cuestiones relacionadas con aspectos económicos, sociales, culturales y ambientales. Como resultado del proceso de investigación, se preparó un diagnóstico preliminar de la realidad y se entregó a la gerencia de la escuela, con la promesa de considerar la investigación en la revisión del Proyecto Pedagógico Político de la escuela, que puede permitir la construcción de prácticas educativas contextualizadas.

Palabras clave: Investigación socioantropológica; Investigación temática; Escuela.

\section{Introdução}

Na busca por um ensino que considere os sujeitos em sua totalidade, vários autores e autoras evidenciam as contribuições do desenvolvimento de práticas educativas de conhecimento do contexto escolar, a partir do diagnóstico preliminar da realidade no qual a escola se insere (Cunha, 2013; Freire, 1979, 2001, 2002, 2011; Freitas et al., 2013; Freitas et al. 2014; Pernambuco, 2002). Com este trabalho buscamos descrever as etapas do processo de construção e desenvolvimento da Pesquisa Socioantropológica (PS), culminando com a elaboração do diagnóstico preliminar da realidade como resultado do processo investigativo. Tal diagnóstico resultou de uma pesquisa realizada em uma escola de Ensino Fundamental, no município de Uruguaiana/RS. Ainda, buscamos apontar algumas contribuições para a fundamentação de práticas contextualizadas, a partir de reflexões teóricas fundamentadas em estudiosos dessa temática e na legislação pertinente à estruturação escolar.

A presente pesquisa foi realizada por bolsistas do subprojeto Ciências da Natureza do Programa Institucional de Bolsa de Iniciação à Docência (Pibid), licenciandos do curso de Ciências da Natureza - Licenciatura da Universidade Federal do Pampa (UNIPAMPA), campus Uruguaiana/RS, com a participação de uma professora de Ciências que integrava o subprojeto. A pesquisa toma por referência os fundamentos da educação libertadora, a partir do estudo da realidade e através de etapas que se aproximam ao método de Investigação Temática proposto por Paulo Freire (2011) e adaptado em estudos publicados por DuqueArrazola e Thiollent (2014), Freitas et al.(2013) e por Pernambuco (2002).

A escola em que a pesquisa foi desenvolvida iniciou suas atividades em 2011 e localiza-se na região sul do município de Uruguaiana, recebendo aproximadamente 900 alunos do $1^{\circ}$ ano ao $9^{\circ}$ ano do Ensino Fundamental. Essa escola atende alunos de diferentes bairros da periferia do município, e grande parte desses alunos encontra-se em situação de 
vulnerabilidade social, compreendendo uma população carente com acesso somente aos serviços básicos, na qual a maioria das famílias é de baixa renda.

Nesse sentido, essa pesquisa emergiu a partir da necessidade de inclusão do diagnóstico da realidade nos documentos oficiais da escola, especialmente no Projeto Político Pedagógico (PPP), visto que o diagnóstico da realidade não constava no referido documento, conforme preconizam as Diretrizes Curriculares Nacionais Gerais para a Educação Básica (Brasil, 2013). Dentre os itens que essa normativa legal elenca para a elaboração do PPP pelas escolas, primordialmente, esse deve ser constituído pelo "diagnóstico da realidade concreta dos sujeitos do processo educativo, contextualizado no espaço e no tempo" (Brasil, 2013, p. $48)$.

Nessa perspectiva, Veiga (1998, p. 11), afirmam que esse documento "nasce da própria realidade, tendo como suporte a explicitação das causas dos problemas e das situações nas quais tais problemas aparecem”. Assim, o PPP é um produto específico que emerge e reflete a realidade da escola, que está situada em um contexto mais amplo que a influencia e que pode ser por ela influenciado. Logo, destaca-se que o PPP exige uma profunda reflexão sobre as finalidades da escola, assim como a explicitação de seu papel social na formação dos sujeitos e a clara definição de caminhos adotados, formas operacionais e ações a serem empreendidas por todos aqueles envolvidos com o processo educativo (Veiga, 1998).

Dessa forma, compreendida a importância da inclusão do diagnóstico da realidade no PPP da escola, destaca-se nesse processo de pesquisa a opção teórico-epistemológica pela pedagogia freireana que dentre seus aspectos, define o método da Investigação Temática para o conhecimento e desvelamento da realidade fundamentais para o planejamento de ações com vistas a transformá-la (Freire, 1978, 2001, 2011).

Este trabalho se estrutura em três partes que se complementam, além desta primeira parte, ao que se segue serão apresentados os fundamentos teóricos e metodológicos, a pesquisa socioantropológica que foi realizada com a narrativa do diagnóstico preliminar da realidade e as considerações finais.

\section{Metodologia: aproximações com etapas da Investigação Temática}

Para a realização deste trabalho, utilizamos a pesquisa socioantropológica como estratégia metodológica, essa se caracteriza por uma abordagem qualitativa de caráter investigativo. Brandão, afirma que "uma das origens da pesquisa socioantropológica da comunidade está nas investigações de realidade social e de levantamento de palavras, temas, 
problemas geradores das experiências de educação popular” (Brandão, 2003, p.129). Ao encontro do que afirmaram os autores, Freitas et al. (2013) afirmam que experiências socioantropológicas se configuram como práticas formativas, tendo como foco $\mathrm{o}$ conhecimento da realidade. As autoras ainda afirmam que "a pesquisa é inerente à ação docente e, sendo assim, tem o sentido ontológico de oportunizar momentos de consciência dos sujeitos sobre a realidade" (Freitas et al., 2013, p. 92).

Ao se planejar e executar a pesquisa socioantropológica, assumem-se características do estudo preliminar da realidade que compõem em uma forma mais ampla e complexa o método da Investigação Temática (IT) proposto por Freire (2011), que trata especificamente da justificativa, explicação e exemplos do que denomina IT, sendo essa definida como a busca pelo conteúdo programático para desenvolvimento de um processo educativo humanista. Sobre o método, o autor discorre que este:

[...] tem de ser uma operação simpática, no sentido etimológico da expressão. Isto é, tem de constituir-se na comunicação, no sentir comum uma realidade que não pode ser vista mecanicamente compartimentada, simplisticamente bem - "comportada", mas, na complexidade de seu permanente vir a ser. [...] A investigação temática, envolve a investigação do próprio pensar do povo. Pensar que não se dá fora dos homens, nem num homem só, nem no vazio, mas nos homens e entre os homens, e sempre referido à realidade (Freire, 2011, p. 140).

Além dos autores já mencionados, Duque-Arrazola \& Thiollent (2014), ao compilarem os textos produzidos por João Bosco Guedes Pinto e teorizarem sobre o método de IT dirão que essa é "uma metodologia de aproximação à realidade de uma comunidade, que busca unir a investigação à ação, com o objetivo de levar a cabo uma programação educativa, desenvolvendo uma ação cultural de conscientização" (Ibidem, 2014, p. 94). Esses autores incluem o método da IT dentro do que caracterizam como metodologias participativas e afirmam ainda que o método se torna um "instrumento de penetração na realidade históricocultural" (Duque-Arrazola \& Thiollent, 2014, p. 95).

Para alcançar os objetivos do conhecimento e interpretação da realidade, a metodologia de IT adapta-se segundo os objetivos e proposições de cada pesquisa realizada (Ibidem, 2014). Sendo assim, assume-se neste trabalho a soma de esforços teórico-práticos de diferentes autores, tendo por base o estudo proposto por Freire (2011) que apresenta o método, posteriormente organizado por Duque-Arrazola e Thiollent (2014), em 3 (três) grandes dimensões, iniciando pela Investigação, passando pela Tematização e sendo concluído com a Problematização. 
A análise dos escritos de Pernambuco (2002) evidencia a presença de 5 (cinco) etapas intrínsecas nas dimensões sugeridas por Ibidem (2014) que foram sistematizadas por Delizoicov, são elas: a) levantamento preliminar da realidade; b) análise das informações coletadas; c) círculo de investigação temática; d) estudo das possibilidades temáticas a partir da análise; e) desenvolvimento do trabalho a partir do estudo. A realização da pesquisa aqui apresentada perpassa todas as etapas de forma aproximada, sendo essas retomadas e discutidas no decorrer do trabalho. A síntese das etapas teórico-metodológicas pode ser vista na Figura 1 abaixo em um organograma, representando o método de IT proposto por Paulo Freire (2011), contendo as dimensões identificadas por Duque-Arrazola \& Thiollent (2014) e destas dimensões partem as etapas sugeridas por Marta Pernambuco (2002).

Figura 1. Organograma síntese das etapas teórico-metodológicas da pesquisa.

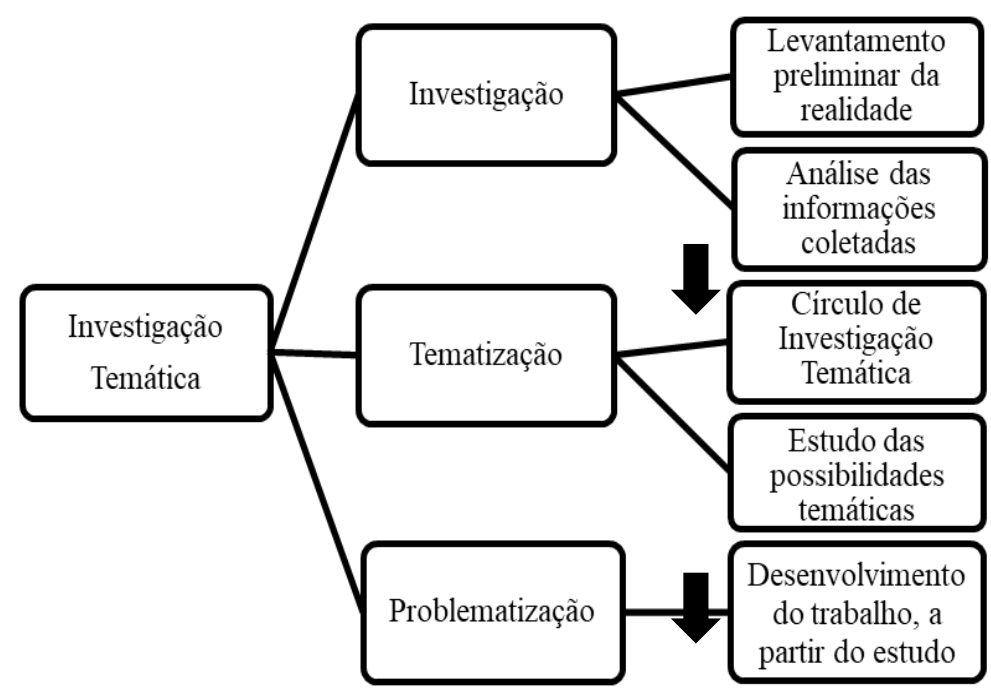

Fonte: Elaborado pelos autores, adaptado de Freire (2011), Duque-Arrazola e Thiollent (2014) e Pernambuco (2002).

Para a realização da pesquisa, foram utilizados questionários semiestruturados como instrumentos de produção das informações, constituindo-se como roteiros pré-determinados, que conduzem o pesquisador, permitindo que esse não se limite apenas às questões escolhidas. Triviños (1987, p. 152) afirma que as entrevistas e os questionários semiestruturados favorecem não só a descrição dos fenômenos sociais, "mas também sua explicação e a compreensão de sua totalidade, além de manter a presença consciente e atuante do pesquisador no processo de coleta de informações".

Os questionários foram construídos de maneira direcionada para cada grupo de 
sujeitos que compõem a comunidade escolar, ou seja, alunos dos anos iniciais $\left(1^{\circ}\right.$ ano ao $5^{\circ}$ ano) e finais ( $6^{\circ}$ ano ao $9^{\circ}$ ano), funcionários dos diferentes setores, professores dos anos iniciais e finais (incluindo equipe pedagógica e diretiva), familiares, pais/mães e responsáveis dos alunos que moram nos bairros que circundam a escola. Os questionários utilizados com os alunos e familiares foram elaborados a partir de 4 (quatro) blocos temáticos, são eles: Bloco 1 - Pessoal/familiar: características pessoais e familiares; Bloco 2 - Comunidade: características do bairro onde moram, tais como: transporte, segurança, saúde, saneamento, meio ambiente, condições de moradia, políticas públicas e qualidade de vida; Bloco 3 Escola: percepções sobre a escola e suas perspectivas de futuro, bem como a importância da escola na sua formação; Bloco 4 - Social: temas de convivência em sociedade, respeito, preconceito, planejamento familiar, gravidez e prevenção de doenças. Essas dimensões dos blocos foram coletivamente construídas, seguindo as orientações dos professores na perspectiva de abordar e reconhecer de forma ampla o contexto em que a escola está inserida. Essa construção integra a primeira etapa de levantamento preliminar da realidade, em que se encontra também o planejamento inicial das ações (Pernambuco, 2002).

Para a aplicação dos questionários com os alunos dos anos finais foram escolhidos 10 (dez) alunos aleatórios de cada turma para preencher o questionário sob a orientação dos bolsistas ID. Os alunos dos anos iniciais responderam às questões com o auxílio da professora responsável pela turma, que sintetizou a opinião dos estudantes.

Os questionários para os professores, estagiários e funcionários foram estruturados com questões sobre a escola, como essa era percebida, quais eram as dificuldades encontradas, pontos positivos que deveriam ser exaltados, bem como percepções sobre os alunos e a comunidade. A pesquisa com os professores e funcionários da escola foi realizada em um momento de formação pedagógica coletiva, em que foram retomados os objetivos da pesquisa e a importância da participação de todos os sujeitos que ocupam o espaço da escola. Neste momento, participaram cerca de 30 (trinta) professores e 12 (doze) funcionários.

A visita aos bairros foi planejada, considerando os bairros que continham o maior número de alunos moradores. Nesse sentido, foi escolhido um bairro que apresentava quase que a totalidade de alunos da escola. Para a visitação às casas das famílias, foram convidados alunos, moradores do local, para conduzirem os bolsistas ID, incorporando os alunos como sujeitos participantes do processo de pesquisa. No total foram entrevistadas 11 (onze) famílias de alunos, sendo que na análise posterior, cada família foi considerada como 1 (um) sujeito investigado. O total de participantes dessa pesquisa está representado no Quadro 1 (um) a seguir: 
Research, Society and Development, v. 9, n. 7, e514974330, 2020

(CC BY 4.0) | ISSN 2525-3409 | DOI: http://dx.doi.org/10.33448/rsd-v9i7.4330

Quadro 1 - Amostra de participantes da pesquisa.

\begin{tabular}{cc}
\hline Participantes Pesquisados (as) & Número de participantes \\
\hline Alunos dos anos iniciais & 52 \\
\hline Alunos dos anos finais & 147 \\
Professores e Gestores & 30 \\
Funcionários & 12 \\
Famílias & 11 \\
Total & 252 \\
\hline
\end{tabular}

Fonte: Elaborado pelos autores.

O conhecimento da realidade do entorno da escola soma-se às investigações realizadas com os alunos e professores de todos os níveis, gestores e funcionários da escola e a interpretação de tais informações constituíram o diagnóstico escolar. Esse diagnóstico passou pela análise, contribuições e aprovação de representantes de todos os segmentos da comunidade escolar para posterior inclusão no PPP. Na sequência desse trabalho, serão apresentadas a pesquisa socioantropológica realizada e o diagnóstico preliminar da realidade que foi elaborado.

\section{Resultados e Discussão}

A construção dos questionários tomou por base a proposta de Freitas et al. (2013, p. 101) que apresenta o "roteiro para elaboração do dossiê socioantropológico". O documento consultado apresentava determinadas questões, direcionadas a um contexto específico, visto que cada instrumento deve ser (re)construído na perspectiva de interpretar diferentes contextos. Com isso, os questionários foram discutidos e construídos de acordo com uma análise preliminar da realidade observada. Freitas et al. (2013, p. 93) afirmam que com a produção coletiva do instrumento de investigação, não apenas se busca interpretar o contexto, mas sim, "a produção de informações da realidade escolar". A realidade escolar torna-se então "o ponto de partida" do método da IT, conforme definem Duque-Arrazola e Thiollent (2014, p. 101).

Construídos os instrumentos de investigação, inicia-se a etapa que Pernambuco (2002) denomina como levantamento preliminar da realidade. A pesquisa iniciou nos anos finais, a 
partir da escolha aleatória de 10 (dez) alunos de cada turma, que ao serem convidados para participar do estudo se disponibilizaram a contribuir com o processo investigativo. A proposta do estudo foi explicada pelos bolsistas ID que esclareceram a importância do estudo para a qualificação das práticas educativas desenvolvidas na escola, bem como, auxiliaram na interpretação das questões que os sujeitos investigados consideravam complexas ou de difícil compreensão. Dessa forma, a atuação dos bolsistas ID durante o processo permitiu a compreensão e reflexão crítica da realidade dos participantes, ao encontro do que foi evidenciado por Freire, quando o autor afirma que o ser humano não participa de forma ativa na história, na sociedade, na transformação da realidade se não for ajudado a tomar consciência da realidade e da sua própria capacidade para transformar (Freire, 2011).

Conforme os questionários eram respondidos, os alunos retomavam suas experiências e percepções acerca do contexto da sua escola, moradia e comunidade, evidenciando aquilo considerado por esse como um problema e que necessitava de determinadas soluções. Nesse momento, os bolsistas ID auxiliavam na reflexão sobre o papel dos agentes públicos para a solução dos problemas identificados, bem como a capacidade de transformação da realidade pelos próprios sujeitos, a partir do protagonismo na construção da sociedade, mediado pelo processo educativo que estava sendo oportunizado na escola. Evidencia-se a participação de professores em formação, bolsistas ID, em espaços de construção e reflexão da realidade escolar por meio de processos investigativos, em que o professor em formação "precisa ter uma visão ampla e profunda sobre a complexa realidade em que se insere a sua prática educativa, bem como refletir sobre o sentido ético e político da mesma" (Silva \& InfanteMalachias, 2012, p. 225).

Com os alunos dos anos iniciais, foi proposto que as professoras utilizassem os mesmos questionários construídos para os alunos dos anos finais, porém com uma dinâmica diferente de produção das informações. As professoras utilizaram-se dos questionários como roteiros para discussão das questões de forma oral, registrando o que consideravam pertinente para o desenvolvimento da pesquisa. Esse método diferenciado foi negociado com as professoras, visto que nos anos iniciais os alunos estão em processo de desenvolvimento da compreensão dos fenômenos, necessitando da explicitação das situações reais. Cabe destacar também que, as professoras, ao discutirem o questionário, buscaram esclarecer para os alunos dos anos iniciais a importância do estudo da realidade para o conhecimento das relações concretas estabelecidas dentro e fora da escola. Duque-Arrazola e Thiollent (2014, p. 98) apontam que a essência dos fenômenos não pode ser definida por meio de sua percepção imediatista, mas é definida, como "feixes de relações e processos, a partir dessas relações e 
como produtos desses processos". Ao mesmo tempo em que tais práticas de reflexão e conhecimento da e sobre a realidade são desenvolvidas, os sujeitos imersos nesse processo produzem as informações e por elas são constituídos.

Os próximos sujeitos participantes da pesquisa foram professores dos anos iniciais e finais, funcionários de diferentes setores de atuação na escola, bem como a equipe pedagógica e diretiva da escola e, ainda: estagiários os quais atuavam na escola no momento da realização da pesquisa. Para esse momento de participação dos profissionais da escola, organizou-se um encontro de formação, em que foram apresentadas e retomadas as propostas da PS, os objetivos, os métodos, assim como a importância da participação desses na construção do diagnóstico, visto que essa conscientização da necessidade de inclusão do diagnóstico no PPP partiu dos bolsistas ID e do coletivo de professores da escola. A participação dos profissionais no processo de investigação é definida por Paulo Freire (2002, p. 41) como um momento, em que se tem clareza da prática docente, sendo que é "preciso conhecer as diferentes dimensões que caracterizam a essência da prática, o que me pode tornar mais seguro no meu próprio desempenho".

A participação dos profissionais que atuam na escola, com destaque para os professores, permitiu além da inclusão das práticas e percepções desses sujeitos na construção do diagnóstico, a reflexão sobre a própria prática docente, seus efeitos e potencialidades. Nessa direção, Freire (2002, p. 24) pontua que "às vezes, mal se imagina o que pode passar a representar na vida de um aluno um simples gesto do professor. O que pode um gesto aparentemente insignificante valer como força formadora”. Nesse movimento de busca, não se pode imaginar como os alunos se relacionam diante das diferentes situações da realidade sendo que "não é possível transformar a realidade concreta na realidade imaginária." (Freire, 2011, p. 53). Ao encontro do que foi afirmado por Freire (2011), Fischman \& Sales afirmam que:

Como professores, estamos convencidos de que a maioria de nós sabe que não pode transformar o mundo através da educação, mas, de qualquer forma, alguns de nós sentimos o comprometimento de intervir, provavelmente não de forma heroica, mas de maneira simples e menos intimidadora, para preservar em nós mesmos as possibilidades de transformar o mundo educativo (Ibidem, 2010, p. 16).

Após a realização da pesquisa com os sujeitos que ocupam o espaço da escola, partiuse para o reconhecimento do seu entorno. Esse momento é considerado como o marco fundamental do desenvolvimento da pesquisa, pois é no contato com a realidade concreta e existencial que as reais dimensões das condições sociais são percebidas. Ao vivenciar a 
realidade dos bairros que compõem o entorno da escola, foi possível compreender de forma mais clara, a atual condição descrita nos questionários, além de se perceber aquilo que não foi possível de ser apreendido com a aplicação desses instrumentos.

Freire (1978) manifesta que o ser humano, da mesma forma que transforma a realidade em que vive, com o mundo e com os outros, se transforma. Contudo, não se é capaz de captar o dado da realidade, o fenômeno, a situação problemática de maneira pura. Na captação, juntamente com o problema, com o fenômeno, capta-se também os nexos causais. Apreende a causalidade das contradições que se instituem durante o processo de desenvolvimento da humanidade (Freire, 1978). Freire apresenta alguns questionamentos sobre a importância de discutirmos a realidade na escola, são estes:

Por que não discutir com os alunos a realidade concreta a que se deva associar a disciplina cujo conteúdo se ensina, a realidade agressiva em que a violência é a constante e a convivência das pessoas é muito maior com a morte do que com a vida? Por que não estabelecer uma necessária "intimidade" entre os saberes curriculares fundamental aos alunos e a experiência social que eles têm como indivíduos? Por que não discutir as implicações políticas e ideológicas de tal descaso dos dominantes pelas áreas pobres da cidade? (Freire, 2002, p. 17).

Percorrendo os questionamentos de Freire, relacionando com o estudo realizado, reflete-se que, independentemente do contexto que a escola está inserida, é preponderante conhecer sua realidade, para que os sujeitos dessa realidade se reconheçam e saibam de que forma podem atuar sobre ela para transformá-la. Os espaços educativos se inscrevem em bairros e localidades que compreendem a totalidade de cada cidade. Sobre isso, Freire afirmou que:

A Cidade se faz educativa pela necessidade de educar, de aprender, de ensinar, de conhecer, de criar, de sonhar, de imaginar de que todos nós, mulheres e homens, impregnamos seus campos, suas montanhas, seus vales, seus rios, impregnamos suas ruas, suas praças, suas fontes, suas casas, seus edifícios, deixando em tudo o selo de certo tempo, o estilo, o gosto de certa época. A cidade é cultura, criação, não só pelo que fazemos nela e dela, pelo que criamos nela e com ela, mas também é cultura pela própria mirada estética ou de espanto, gratuita que lhe damos. A Cidade somos nós e nós somos a Cidade (Freire, 2001, p. 22-23).

Partindo dessa leitura e, indo ao encontro do que afirma Freire (2001), Cunha (2013) salienta que a cidade é um convite para que a escola estenda seu currículo em direção à realidade, ocupando-a, caminhando por ela, apreciando seu traçado, pulando suas valas, respirando suas casas, praças, museus, bares, esquivando seus imprescindíveis automóveis, 
percebendo a cidade e o entorno como patrimônio cultural e curricular, em um dado espaço e tempo. Cunha (2013) ainda explicita que uma das principais indisposições de jovens para o currículo escolar é o caráter rotineiro e previsível das salas de aulas e das escolas. Para o autor, o currículo escolar deve possibilitar a surpresa, o inesperado, um ambiente escolar onde o "cadeado seja aberto rotineiramente, para deixar sair e entrar o mundo" (Cunha, 2013, p. 64).

As entrevistas, como já mencionadas, foram realizadas pelos bolsistas ID e por alunos da escola que conduziram os investigadores pelos bairros. Nessa busca, realizaram-se 11 (onze) entrevistas com familiares e responsáveis pelos alunos da escola.

Após o reconhecimento do entorno da escola, parte-se para a análise das informações coletadas. Nesse momento, os bolsistas ID juntamente com a professora de Ciências categorizaram as respostas, aproximando as respostas semelhantes e considerando as situações pertinentes aos objetivos iniciais da PS.

Essa primeira etapa de pesquisa, segundo Freire é capaz de fazer com que os investigadores se apropriem, "através de suas observações, dos núcleos centrais daquelas contradições, os investigadores já estariam capacitados para organizar o conteúdo programático da ação educativa” (Freire, 2011, p. 148). Realizado esse primeiro momento da pesquisa, alocado na dimensão denominada Investigação proposta por Pernambuco (2002), a próxima etapa chama-se Tematização. Nessa etapa as informações são decodificadas e sistematizadas, construindo-se um programa que efetive a utilização de propostas pedagógicas que tomam por base o arcabouço de informações produzidas pela PS. A primeira etapa dessa dimensão é a realização do círculo de investigação temática.

O círculo de investigação temática pode ser compreendido como a análise reflexiva e aprofundada das informações que os instrumentos foram capazes de apreender dos sujeitos investigados, buscando sintetizar as informações, otimizando a investigação dos "Pré-temas", conforme afirma Pernambuco (2002, p. 72). Na busca pelos Pré-temas, devem ser consideradas as situações problemas que se apresentam a partir da análise das respostas, buscando o que Freire afirmou serem os "aspectos concretos de suas necessidades sentidas" (Freire, 2011, p. 154).

Ao serem elencados os temas pertinentes para a construção do diagnóstico da realidade, consideraram-se circunstâncias recorrentes nas diferentes análises. Pernambuco (2002, p. 83) afirma que "compreender a realidade em seus múltiplos é mais do que perceber vagamente que existem relações entre eles. É na percepção de como, quando e onde essas relações se estabelecem que podemos ir além da visão primeira, genérica". Nesse sentido, 
quando se debruça sobre as situações com um olhar investigativo procura-se perceber não somente os fatos isolados, mas as condições do contexto que propiciaram que o fato acontecesse, resultando assim na trama de relações sociais, históricas e culturais que constituem a realidade e os sujeitos que nela residem. É nesse momento, que o esforço coletivo dos pesquisadores, bolsistas ID e professora de Ciências devem perceber aquilo que consideram pertinente para a construção do diagnóstico da realidade, posteriormente inserido no PPP, culminando na condução dos planejamentos e organizações dos professores para o trabalho em sala de aula.

Neste momento de busca pelos Pré-temas (Pernambuco, 2002), que Paulo Freire chamou de busca pelos Temas Geradores (Freire, 2011), a coletividade se mostra substancial para a realização do trabalho, em um esforço prático de decodificação das situações, que na obra original de Freire (2011) deve ser realizada por especialistas de diferentes áreas, assim como por representantes da comunidade na compreensão das situações problemas. Contudo, como já se assumiu anteriormente, para este trabalho não foram seguidas com rigor todas as proposições do método de IT, uma vez que, participaram da decodificação os bolsistas ID e a professora de Ciências.

A busca pelos Pré-temas torna-se uma tarefa complexa, de leitura e releitura do que foi desenvolvido na tentativa de se capturar aquilo que pode gerar trabalhos, com vistas à resolução dos problemas encontrados na comunidade. Freire (2011, p. 110) considera que "esses temas se chamam geradores porque, qualquer que seja a natureza de sua compreensão como a ação por eles provocada, contêm em si a possibilidade de desdobrar-se em outros tantos temas". A investigação/busca dos temas geradores "implica, necessariamente, uma metodologia que não pode contradizer a dialogicidade da educação libertadora. Daí que seja igualmente dialógica" (Freire, 2011, p. 87). Posterior ao "Círculo de Investigação Temática" inicia-se o "Estudo das Possibilidades Temáticas", última etapa da dimensão Tematização do Método IT.

O Estudo das Possibilidades Temáticas é o momento de reunir, organizar e sistematizar as informações contidas nos Pré-temas/Temas Geradores, de forma coletiva, que nesta pesquisa constituem-se como o diagnóstico preliminar da realidade. O diagnóstico preliminar da realidade construído resulta do processo de realização da PS que teve como objetivo capturar informações sobre o contexto escolar para inclusão no PPP da escola, assim como fundamentar os planejamentos pedagógicos, considerando a realidade dos alunos para a realização de um trabalho contextualizado como se propõe o método de IT. 
Com a realização da pesquisa socioantropológica constatamos que a maioria dos alunos habita casas de alvenaria em bom estado de conservação, pois o bairro que concentra o maior número de alunos é oriundo do loteamento de casas populares ofertado pelos poderes públicos. As famílias, no geral, são numerosas, com uma média de 9 pessoas por residência, constituídas de forma nuclear por mãe, pai ou padrasto, e que as que fogem a esse modelo, os filhos vivem com a mãe, avós e tios. Grande parte dos pais e responsáveis possui baixa escolaridade (Ensino Fundamental incompleto) e trabalha em funções informais de prestação de serviço, em que se evidencia o auxílio do Bolsa Família como complemento à renda. As mulheres atuam como domésticas, faxineiras ou diaristas; já os homens desempenham funções de motoristas ou pedreiros em sua grande maioria. Um número expressivo de pessoas com deficiências físicas e cognitivas compõe as famílias dos alunos, destacando-se as pessoas cadeirantes por inúmeros motivos, atraso no desenvolvimento motor, pessoas com déficit cognitivo, além de pessoas com Síndrome de Down. Ainda, outras doenças comprometem a saúde das famílias dos alunos entrevistados, são elas: diabetes, diversos tipos de câncer, asma, osteoporose e hipertensão.

Percebeu-se inúmeras ocorrências de gravidez na adolescência, sobretudo, no momento da realização da pesquisa, identificaram-se vários casos na escola de alunas adolescentes grávidas ou que já se tornaram mães, algumas delas estavam grávidas pela segunda vez. Considerando esse quadro, é importante destacar que a comunidade, em geral, demonstrou pouco conhecimento sobre os métodos contraceptivos existentes, citando apenas a camisinha masculina e o anticoncepcional oral como formas de prevenção às doenças e à gravidez.

Sobre a alimentação saudável, a opinião de considerar uma refeição equilibrada se restringe ao consumo de legumes, frutas e verduras, entretanto, verificou-se que o consumo de alimentos calóricos predomina nas refeições da maioria dos alunos. Vale destacar, que nem todos têm conhecimento e/ou condições financeiras de realizar uma dieta equilibrada.

Pode-se considerar que os alunos reconhecem o armazenamento adequado e destino do lixo produzido em suas residências, mas poucos afirmaram que realizam a separação adequada do lixo, mesmo demonstrando ter conhecimento sobre o programa de coleta seletiva. Os sujeitos participantes identificaram diversos problemas ambientais, tais como: depósitos irregulares de lixo na localidade onde moram, esgoto a céu aberto, animais abandonados nas proximidades, cortes irregulares de árvores, falta de saneamento básico e queima de lixo. Em relação aos animais de estimação, todos os investigados possuem pelo 
menos um gato, cão ou cavalo em casa, visto que, muitos pais e/ou responsáveis, possuem carroça como meio de transporte e obtenção de renda, realizando transporte de cargas.

Quase a totalidade dos alunos tem acesso a meios de informação como rádio, televisão e internet, e muitos afirmaram que costumavam ler revistas e livros com regularidade, assim como seus familiares que evidenciaram a presença frequente da bíblia como objeto de leitura, já que a maioria dos sujeitos entrevistados vão à igreja evangélica, amplamente disseminada no bairro.

Como aspecto positivo do bairro onde residem, destacaram o convívio com a vizinhança e a presença de espaços recreativos, tais como: campo de futebol e praças. Por outro lado, como aspectos negativos evidenciaram a violência, os problemas ambientais (esgoto e lixo), assim como a falta de reparo na pavimentação das ruas. Ainda sobre os aspectos negativos, cabe destacar que a segurança foi o item de maior preocupação, pois a presença de gangues, conhecidas como "bondes", geralmente integrada por muitos jovens e até crianças, causa a sensação de insegurança nos moradores, o que tem relação com a frequência de roubos, brigas e consumo de drogas, aspectos muito destacados pelos entrevistados. Moradores e alunos também relataram que já presenciaram situações de racismo e homofobia, entretanto, não identificaram a presença de preconceito e desvalorização da mulher na sociedade.

Sobre a participação da família na escola, é importante destacar que essa participação não se dá de modo espontâneo, uma vez que as famílias relataram que se fazem presente apenas quando são solicitadas pelos estudantes para solucionar os problemas em que os alunos estão envolvidos e/ou no dia da entrega de notas, em que possuem a possibilidade de conversar com os professores e demais integrantes da escola. Porém, conforme citado por professores, funcionários e equipe diretiva, muitos pais e/ou responsáveis deixam de comparecer à escola na entrega das notas e não fazem o devido acompanhamento. São notórias as expectativas dos pais e/ou responsáveis pelos estudantes em referência à escola, pois esperam que a escola ofereça segurança para que os mesmos concluam os estudos, com a possibilidade de um futuro, minimamente, promissor.

Considerando os aspectos acima apresentados sobre o diagnóstico da realidade da escola, destaca-se que esse processo oportunizou que os profissionais da educação da escola e bolsistas ID percebessem as situações problemáticas do contexto no qual estavam inseridos para, a partir desse conhecimento, pensarem e proporem intervenções na escola de um modo geral. Como um dos resultados da PS destaca-se a inserção do diagnóstico no PPP da referida escola, aspecto fundamental para a construção de um trabalho contextualizado, elencando 
conteúdos conceituais, procedimentais e/ou atitudinais, pertinentes a um componente curricular, projeto, programa ou ação (Freitas et al., 2013).

Nesse sentido, Freire (2011, p. 100) afirma que "a partir da situação presente, existencial, concreta, refletindo o conjunto de aspirações do povo, que poderemos organizar o conteúdo programático da educação”. Na concepção do autor, contextualizar é, portanto, refletir a partir da realidade, compreendendo a vida e os processos de construção e desenvolvimento da sociedade em seus diversos aspectos. Contextualização aproxima-se do que o autor afirma ser a problematização das situações existenciais, pois não basta relacionar o conteúdo com a realidade, mas devem ser identificadas situações problemáticas da realidade sobre as quais os sujeitos que aprendem podem se voltar para transformá-las. Freire (2011, p. 100) nos diz que, enquanto educadores, no desenvolvimento da nossa prática, deve-se "propor ao povo, através de certas contradições básicas, sua situação existencial, concreta, presente, como problema que, por sua vez, o desafia e, assim, lhe exige resposta, não só no nível intelectual, mas no nível da ação”.

Para o desenvolvimento de um trabalho educativo contextualizado, podemos buscar argumentos e fundamentação na Lei de Diretrizes e Bases da Educação Nacional (Brasil, 1996), ao dispor, em seu Artigo $1^{\circ}$, inciso $2^{\circ}$, que a "educação escolar deverá vincular-se ao mundo do trabalho e à prática social” (Brasil, 1996, p. 9). Dessa maneira, para vincularmos a educação com a prática social, deve-se considerar quais práticas são desenvolvidas, assim como de que maneira a relação com os conteúdos e sua inserção na realidade acontecerá.

É importante que uma das condições para o acontecimento do ensino contextualizado seja o (re)conhecimento dos sujeitos do processo de ensino-aprendizagem, de suas experiências e entendimento do mundo, conforme realizado no processo de construção da PS que resultou no diagnóstico da realidade escolar. O entendimento crítico é o que se quer desenvolver, de modo que a criticidade na leitura das situações não é pressuposto, mas a consciência sobre as situações que vai passando de ingênua para crítica. O processo também é essa busca por contradições do que acontece, como acontece, para quem acontece e por que acontece.

Além disso, é importante destacar que a valorização da experiência extraescolar configura como um princípio fundamental para o desenvolvimento de um ensino contextualizado, conforme preconizam as Diretrizes Curriculares Nacionais Gerais para a Educação Básica (Brasil, 2013). Essa compreensão, de que os saberes prévios devem ser considerados durante o processo de ensino-aprendizagem, estimulando a problematização da 
realidade e oportunizando a (re)construção do conhecimento é "uma das tarefas fundamentais do educador progressista" (Freire, 2002, p. 50).

Neste item, foram discutidas as principais etapas adotadas para o desenvolvimento da PS, assim como algumas reflexões sobre as contribuições da construção do diagnóstico preliminar da realidade que foi entregue à direção da escola com a promessa de que seria inserido no Projeto Político Pedagógico, na perspectiva de viabilizar o desenvolvimento de práticas educativas contextualizadas. Na sequência, serão apresentadas as considerações finais elencando as principais contribuições do trabalho.

\section{Considerações Finais}

Com o presente trabalho buscamos descrever as etapas do processo de construção e desenvolvimento da Pesquisa Socioantropológica (PS), culminando com a elaboração do diagnóstico preliminar da realidade como resultado do processo investigativo. Inicialmente destacamos que a PS fundamentada no método de Investigação Temática configura-se como viável de ser realizada e como uma possibilidade de compreensão dialógica do contexto. Como resultado da OS, destaca-se a produção do diagnóstico preliminar da realidade, fundamental para desencadear uma proposta de ensino contextualizado.

Para a elaboração do diagnóstico preliminar da realidade é imprescindível o envolvimento coletivo e cooperativo de grande parte dos sujeitos envolvidos, garantindo, assim, a apreensão mais complexa dos aspectos que envolvem o contexto escolar. Nesse processo investigativo, destaca-se que a atuação dos bolsistas ID na escola contribuiu com a realização da PS, permitindo vivenciar um pouco dos princípios de uma educação libertadora e humanista descrita por Paulo Freire, bem como, atuar em uma comunidade escolar rica em oportunidades de desenvolvimento de temas relevantes para serem abordados em sala de aula, tais como: educação ambiental, saúde e prevenção, diversidade cultural e inclusão social. Cabe destacar que o diagnóstico preliminar da realidade foi entregue à direção com a promessa de inclusão no Projeto Político Pedagógico da escola investigada, o que pode provocar reformulações e adequações na organização curricular, planejamento e funcionamento da escola.

Para finalizar, consideramos que a PS além de configurar-se num processo investigativo, também contribui com a formação dos sujeitos envolvidos, que se dá através da busca por referenciais teóricos, na construção coletiva e cooperativa dos instrumentos de produção e análise das informações, especialmente, promovendo práticas educativas 
dialógicas, através de debates, discussões e reflexões que possam colaborar na construção de novos saberes e na transformação da escola.

\section{Agradecimentos}

À Coordenação de Aperfeiçoamento de Pessoal de Nível Superior (CAPES), Brasil, pelo financiamento do Programa Institucional de Bolsa de Iniciação à Docência, subprojeto Ciências da Natureza.

\section{Referências}

Brandão, CRA. (2003). Pergunta a várias mãos: a experiência da pesquisa no trabalho do educador. São Paulo: Cortez.

Brasil. (1996). Lei no 9. 394, de 20 de dezembro de 1996. Estabelece as Diretrizes e Bases da Educação Nacional. Ministério de Educação. Brasília.

Brasil. (2013). Diretrizes Curriculares Nacionais Gerais para a Educação Básica. Ministério de Educação. Brasília.

Brasil. (2013). Lei n. 12.796, de 04 de abril de 2013. Altera a Lei $\mathrm{n}^{\circ}$ 9.394, de 20 de dezembro de 1996, que estabelece as diretrizes e bases da educação nacional, para dispor sobre a formação dos profissionais da educação e dar outras providências. Ministério de Educação. Brasília.

Cunha, ALÁ. (2013). Corpo-ambiente-cultura na formação de professores/as. In: Silveira, MICM; Bianchi, P. (Orgs). Núcleo Interdisciplinar de Educação. Articulação de contextos \& saberes nos (per)cursos de licenciatura da Unipampa. Florianópolis: Tribo da Ilha:

Duque-Arrazola, LS \& Thiollent, MJM. (2014.). João Bosco Guedes Pinto. Metodologia, teoria do conhecimento e pesquisa-ação: textos selecionados e apresentados. Belém: Universidade Federal do Pará. 
Fischman, GE \& Sales, SR. (2010). Formação de professores e pedagogias críticas. É possível ir além das narrativas redentoras?. Revista Brasileira de Educação, 15(43). doi: https://doi.org/10.1590/s1413-24782010000100002.

Freire, P. (1978). Educação como Prática da Liberdade. 8. ed. Rio de Janeiro: Paz e Terra.

Freire, P. (1979). Conscientização: teoria e prática da libertação - uma introdução ao pensamento de Paulo Freire. 2.ed. São Paulo: Moraes.

Freire, P. (2001). Política e Educação: ensaio. 6. ed. São Paulo: Cortez.

Freire, P. (2002). Pedagogia da autonomia: saberes necessários à prática educativa. 21. ed. São Paulo: Paz e Terra.

Freire, P. (2011). Pedagogia do Oprimido. 50. ed. Rio de Janeiro: Paz e Terra.

Freitas, DPS, Silva, FF, Lindemann, RH \& Mello, EMB. (2013). Dossiê Socioantropológico: reflexões e práticas para o estudo da realidade. In: Silveira, MICM, Bianchi, P. (Orgs). Núcleo Interdisciplinar de Educação: Articulação de contextos \& saberes nos (per)cursos de licenciatura da Unipampa. Tribo da Ilha: Florianópolis.

Freitas, DPS, Motta, CS \& Mello-Carpes, PB. (2014). As bases neurobiológicas da aprendizagem no contexto da investigação Temática freireana. Revista Trabalho, Educação e Saúde, 13(1). doi: https://doi.org/10.1590/1981-7746-sip00023.

Pernambuco, MMCA. (2002). Significações e realidade: conhecimento. In: Pontuschka, N. N. (Org). Ousadia no Diálogo: interdisciplinaridade na escola pública. 4.ed. São Paulo: Loyola.

Silva, A. C. da \& Infante-Malachias, ME. (2012). Reflexões sobre a convergência do pensamento de Paulo Freire e de Edgar Morin: contribuições para a formação docente. Cadernos de Educação, 42(2). doi: http://dx.doi.org/10.15210/caduc.v0i42.2155.

Triviños, A. (1987). Introdução à pesquisa em ciências sociais: a pesquisa qualitativa em educação. São Paulo: Atlas. 
Veiga, IPA. (1998). Perspectiva para reflexão em torno do Projeto Político-Pedagógico. In: Veiga, IPA \& Resende, LMG. de (Orgs). Escola: espaço do projeto politico pedagógico. Coleção Magistério: Formação e trabalho pedagógico. Campinas: Papirus.

\title{
Porcentagem de contribuição de cada autor no manuscrito
}

\author{
Ronan Moura Franco - 40\% \\ Murilo Ricardo Sigal Carriço - 15\% \\ Rita Cristina Gomes Galarça - $15 \%$ \\ Fabiane Ferreira da Silva - 30\%
}

